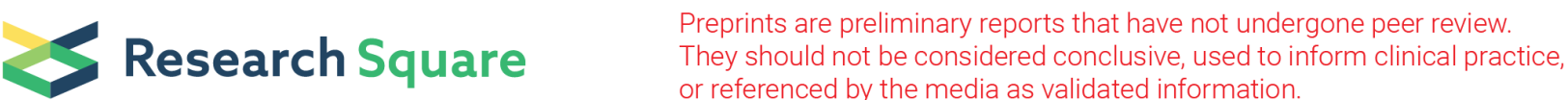

\section{S ilencing of SCD and SREBP1 Genes by Short Hairpin RNAs in Chicken Hepatic Cells in Vitro}

N Govardhana Sagar

Indian Veterinary Research Institute

A Rajendra Prasad

Directorate of Poultry Research

Pushpendra Kumar

Indian Veterinary Research Institute

Bharat Bhushan

Indian Veterinary Research Institute

P Guru Vishnu

Indian Veterinary Research Institute

Tarun K Bhattacharya ( $\square$ bhattacharyatk@gmail.com )

ICAR-Directorate of Poultry Research https://orcid.org/0000-0003-4502-1852

\section{Research Article}

Keywords: Chicken hepatocytes, Knock Down, SCD, shRNAs, SREBP1

Posted Date: January 14th, 2022

DOI: https://doi.org/10.21203/rs.3.rs-626332/v1

License: (c) (1) This work is licensed under a Creative Commons Attribution 4.0 International License. Read Full License 


\section{Abstract}

RNA interference by short hairpin RNAs (shRNAs) is a widely used post transcriptional silencing mechanism for suppressing expression of the target gene. In the current study, five shRNA molecules each against $S C D$ and SREBP1 genes involved in denovo lipid biosynthesis were designed upon considering parameters such as secondary structures of shRNAs, mRNA target regions, GC content and thermodynamic properties ( $\triangle \mathrm{G}$ overall, $\triangle \mathrm{G}$ duplex and $\triangle \mathrm{G}$ breaktarget), synthesized and cloned in pENTR/U6 entry vector to knockdown the expression of SCD and SREBP1 genes. After transfection of these shRNA constructs into the chicken embryonic hepatocytes, expressions of the target genes were monitored by real time PCR. Significant reduction $(P<0.05)$ in the expression of SCD and SREBP1 genes was observed in hepatocytes. The shRNAs against SCD gene showed the knock down efficiency ranged from $20.4 \%$ (shRNA5) to $74.2 \%$ (shRNA2). In case of SREBP1 gene, the shRNAs showed knock-down efficiency ranging from 26.8\% (shRNA4) to 95.85\% (shRNA1). The shRNAs against both the genes introduced in chicken hepatocyte cells did not show any significant impact on expression of immune response genes (IFNA and IFNB) in those cells. These results clearly demonstrated the successful down regulation of the expression of SCD and SREBP1 genes by the shRNA molecules against both the target genes under in vitro condition. It is concluded that the shRNA molecules against SCD and SREBP1 genes showed great potential to silence the expression of these genes under in vitro chicken embryonic hepatocyte cells.

\section{Introduction}

Genetic selection has greatly improved chicken production over the last 50 years which provides high quality dietary protein to mitigate our protein demand. However, intensive genetic selection for rapid growth inadvertently selected for increased carcass fat. Carcass fat in broilers at 6 weeks of age accounts for $10-15 \%$ of the total carcass weight and deposits at a rate of up to $6 \mathrm{~g}$ fat $/ \mathrm{kg}$ body wt/day between 42 and 49 days of age [1]. The predominant site of adipose deposition in chickens is abdominal fat and, to a less extent, subcutaneous fat and intramuscular fat [2]. This is probably because abdominal fat is proportionately the largest when body weights and growth rates are the critical traits under selection. Excess fat is an economic loss to the broiler industry by reducing the conversion of feed to meat, and the disposal of fat leads to additional economic loss. Excess fat may also contribute to the development of other detrimental traits, such as reduced reproductivity and immune competence, which consequently affect growth and yield of meat [3].

Fatty acids in animals can come from diet or be synthesized from glucose in lipogenic tissues such as liver and adipose tissues catalyzed by fatty acid synthase. Dietary fatty acids are absorbed by enterocytes, packaged with cholesterol, lipoproteins and other lipids into chylomicrons, and transported into circulation. Lipids synthesized in the liver are packaged into LDLs and released into the blood directly. TAG-rich VLDL are taken up by adipocytes and deposited into adipose tissue. In chickens, the contribution of portomicrons (similar to chylomicrons in mammals) from dietary fats to triglyceride is low, since there is only $5 \%$ of dietary lipids in regular feed [4]. Triglyceride (TAG) deposits in chicken adipose tissue mainly through the uptake of fatty acids from circulating TAG-rich VLDL synthesized by the liver. Increased VLDL levels were found virtually in chickens associated with high fatness, reflecting the critical role of the liver in fatness of chickens. The contribution of de novo lipogenesis in liver to fat deposition was also confirmed in chicken [5]. Only $15 \%$ of de novo lipogenesis occur in adipose tissue, and the rest is happened in liver [6]. The product of de novo lipogenesis in liver are secreted in the form of VLDL and delivered to other tissues. However, the basic step in the synthesis of lipids is the formation of saturated fatty acids (SFAs) and monounsaturated fatty acids (MUFAs), the major fatty acid species in mammalian cell lipids.

One key regulator of the fatty acid composition of cellular lipids are Stearoyl-CoA desaturases $(S C D)$, the endoplasmic reticulum-resident enzyme that catalyze the introduction of the first double bond in the cis-delta-9 position of several saturated fatty acyl-CoAs, principally palmitoyl-CoA and stearoyl-CoA, to yield palmitoleoyl-and oleoyl-CoA, respectively $[7,8]$. Stearoyl-CoA desaturase $(S C D)$ is an iron-containing enzyme that catalyzes a rate-limiting step in synthesis of the unsaturated fatty acids. The principal product of $S C D$ is oleic acid, which is formed by desaturation of stearic acid.

Sterol regulatory element binding protein-1 (SREBP1) is a transcription factor that binds to a sequence in the promoter of a group of genes, called sterol regulatory element-1 (SRE1). This element is a decamer flanking the LDL receptor gene and other genes involved in sterol biosynthesis. The SREBP1 regulates genes required for glucose metabolism and fatty acid and lipid production and its expression is regulated by insulin [9]. The SREBP1 regulates genes related to lipid and cholesterol production and its activity is regulated by sterol levels in the cell $[10,11]$. The transcription factor SREBP1 regulates de novo lipogenesis in the liver in response to increases in insulin. SREBPs are transcription factors of the basic helix-loop-helix leucine zipper family that are synthesized as precursors and bound to the endoplasmic reticulum membrane. In the present study, we have developed an in vitro model for reduction of SCD and SREBP1 expression in chicken embryonic hepatic cells by the short hairpin RNA molecules.

\section{Materials And Methods}

\section{Experimental animals}

The study was conducted in the control broiler chicken line maintained at ICAR-Directorate of Poultry Research, Rajendranagar, Hyderabad, India. The fertile eggs were collected from control broiler chicken and incubated at $98^{\circ} \mathrm{F}$ and $85 \%$ relative humidity in the incubator for 12 to 13 days. The embryonated eggs of 12-13 days old were taken out for preparation of embryonic hepatocyte primary cell culture. The whole study was approved by the Institute Animal Ethics Committee (IAEC) and Institute Bio-safety Committee (IBSC) of ICAR-Directorate of Poultry Research, Rajendranagar, Hyderabad, India to carry out the animal experiment.

\section{Designing of shRNA molecules:}

A total of 5 shRNA molecules each were designed from ORF of SCD (NCBI Accession No. NC_006093) and SREBP1 (NCBI Accession No. NC_006101) genes using BLOCK-iT RNAi Designer (https://rnaidesigner.thermofisher.com/rnaiexpress/) software (Table 1). To determine efficiency of shRNA molecules, secondary structures of shRNAs were predicted by in silico analysis in the web server of Mfold 2.3 version [12] (http://mfold.rna.albany.edu/?q=mfold/RNA- 
Folding-Form) was used after considering the all the required criteria. Secondary structures of antisense strands of shRNA molecules against $S C D$ and SREBP1 genes were predicted by using the RNA fold program of the Vienna RNA web service version 2.0 [13] (http://rna.tbi.univie.ac.at/cgi-

bin/RNAWebSuite/RNAfold.cgi). Further, Thermodynamic properties that governs the binding affinity of shRNA molecules and its target region on mRNA molecules [15] were predicted by Oligowalk program [14] in the RNA structure version 5.3 (http://rna.urmc.rochester.edu/cgibin/server_exe/oligowalk/oligowalk_form.cgi). Following thermodynamic properties [16] were included in the present study:

i. $\Delta \mathbf{G}$ overall: The net energy $(\Delta \mathrm{G}$ in $\mathrm{kcal} / \mathrm{mol})$ resulting due to binding of target site by oligos, after consideration of all energy contributions viz. oligo-selfstructure energy and target structure breaking energy. The higher negative value of $\Delta \mathrm{G}$ signifies stronger binding.

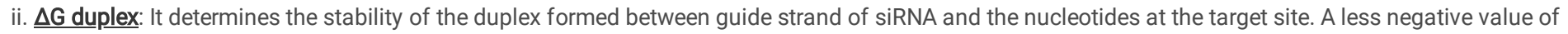
$\Delta \mathrm{G}$ duplex denotes less stability of duplex and vice versa.

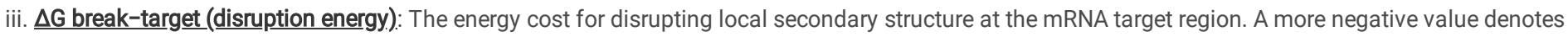
that the binding site is not completely open and less accessible.

\section{Cloning of shRNAs:}

A final concentration of $50 \mu \mathrm{M}$ double stranded oligos were prepared by mixing top strand DNA oligo $(200 \mu \mathrm{M})-5 \mu \mathrm{l}$, Bottom strand DNA oligo (200 $\mu \mathrm{M})$ - $5 \mu \mathrm{l}$, $10 \mathrm{X}$ Oligo annealing buffer $-2 \mu \mathrm{l}$ and DNAse/RNase free water $-8 \mu \mathrm{l}$, by using the conditions $95^{\circ} \mathrm{C}$ for 4 minutes and then allowed to cool at room temperature for 5-10 minutes to obtain double-stranded oligos to anneal.

The ds oligos ( $50 \mu \mathrm{M}$ stock) were diluted to a final concentration of $5 \mathrm{nM}$ by performing two 100 -fold serial dilutions. First 100 -fold dilution was accomplished with DNase/RNase-free water and then second100-fold dilution was completed with $1 \mathrm{X}$ Oligo annealing buffer supplied with the kit. These diluted ds oligos were used for cloning into the pENTR /U6 Entry Vector (Figure.S1). The annealed shRNA oligo nucleotides were ligated into RNAi Ready pENTR ${ }^{\text {TM }}$ U6 vector by preparing $20 \mu$ of ligation mixture containing 5X Ligation Buffer - $4 \mu \mathrm{l}$, pENTRTM /U6 (0.5ng/ì) - $2 \mu$ l, ds oligo (5 nM; 1:10000 dilution) - $1 \mu$ l, T4 DNA Ligase $(1 \mathrm{U} / \mu \mathrm{L})-1 \mu \mathrm{l}$ and DNAse/RNase free water $-12 \mu \mathrm{l}$. This ligation mixture was mixed well and incubated for 30 minutes at room temperature. Scrambled shRNA oligos (lacZ) supplied with the kit were also ligated to pENTR ${ }^{\text {TM}} /$ U6 vector and used as a negative control in the experiment.

Recombinant vector containing the shRNA molecules were transformed into the One Shot ${ }^{\circledR}$ TOP10 chemically competent E.coli cells by giving heat-shock $\left(42^{\circ} \mathrm{C}\right.$ for 30 seconds and then, immediately transferred to ice). Transformed cells were grown in $250 \mu$ of super optimal broth with catabolite repression (S.O.C.) medium at room temperature by incubating in horizontal shaker incubator (200 RPM) at $37^{\circ} \mathrm{C}$ for 1 hour. $200 \mu \mathrm{L}$ of transformation mixture was spread on a pre-warmed LB agar plate containing $50 \mu \mathrm{g} / \mathrm{ml}$ of kanamycin and incubated overnight at $37^{\circ} \mathrm{C}$.

Kanamycin resistant colonies were picked and inoculated into the LB broth containing kanamycin $50 \mu \mathrm{g} / \mathrm{mL}$ of media and incubated over night at $37^{\circ} \mathrm{C}$ to analyze the positive clones. Kanamycin resistant clones were screened for the presence of shRNA in the plasmid constructs by performing colony PCR with U6 forward primer: 5'GGACTATCATA TGCTTACCG3' and M13 reverse primer: 5'-CAGGAAACAGCTATGAC-3' by using $2.5 \mu \mathrm{L}$ of $10 \mathrm{XPCR}$ buffer, $0.5 \mu \mathrm{L}$ of dNTP mix $(2.5 \mathrm{mM}), 1.5 \mu \mathrm{L}(30 \mathrm{ng})$ each of forward and reverse primers, $0.2 \mu \mathrm{L}(1 \mathrm{U})$ of Taq DNA polymerase, $2 \mu \mathrm{L}$ of colony lysate and nuclease free water to make the volume up to $25 \mu \mathrm{L}$ in $0.2 \mathrm{ml} \mathrm{PCR}$ tubes. Thermal cycling conditions followed were, initial denaturation at $95^{\circ} \mathrm{C}$ for 10 minutes followed by 35 cycles of denaturation at $95^{\circ} \mathrm{C}$ for 30 seconds, primer annealing of $54^{\circ} \mathrm{C}$ for 30 seconds and extension at $72^{\circ} \mathrm{C}$ for 30 seconds and final extension of $72^{\circ} \mathrm{C}$ for 10 minutes.

Plasmids containing shRNA molecules against SCD and SREBP1 genes were isolated by using Gene JET Plasmid Miniprep Kit (\#K0503, Thermo Scientific, USA). The plasmid obtained from each $\mathrm{pENTR} \mathrm{R}^{\mathrm{TM}} / \mathrm{U} 6$ entry construct was sequenced to confirm the sequence and correct orientation of the ds oligo insert.

\section{Establishment of primary chicken embryonic hepatocyte (CEH) culture:}

Primary chicken embryonic hepatocyte culture was established by using 12-13 days old embryos. Embryos were collected aseptically by breaking the broad end of the egg after piercing the chorio-allantoic membrane (CAM) and placed in $9 \mathrm{~cm}$ petri-dish containing sterile Phosphate Buffer Saline (PBS) and rinsed thoroughly. Head, limbs and wings were separated and then, ventral side of the embryo was cut opened for collecting the liver lobes into the petri-dish containing the PBS. After thorough washing in PBS and mincing, liver tissues were transferred into the beaker containing sterile magnetic bar and approximately $10-15 \mathrm{ml}$ of $0.125 \%$ trypsin. The beaker was placed on the magnetic stirrer for stirring at $37^{\circ} \mathrm{C}$ at about $100 \mathrm{RPM}$ for less than $10 \mathrm{minutes}$. After allowing the pellets to settle down, supernatant was filtered through sterile double layered muslin cloth into a fresh beaker. The filtrate was centrifuged for 5 minutes at 3000 RPM and to stop the trypsin action, the resulting pellet was re-suspended in $5 \mathrm{ml}$ of growth medium (DMEM, Sigma) containing Fetal Bovine Serum (FBS). Now, the media with the liver cells were centrifuged at 3000 RPM for $3 \mathrm{~min}$ and then, the resulting pellet was re-suspended in $5 \mathrm{ml}$ of growth medium containing $10 \%$ FBS, $1 \%$ Tryptone Phosphate Broth and antibiotic-antimycotic solution. Haemocytometer was used to count the number of cells and accordingly, the cell suspension was diluted to get a cell concentration of $1 \times 10^{6}$ cells $/ \mathrm{ml}$. Approximately $2 \times 10^{5}$ cells $/ \mathrm{cm}^{2}$ were seeded into the $25 \mathrm{~cm}{ }^{2}$ tissue culture flask and incubated at $37^{\circ} \mathrm{C}$ with $5 \% \mathrm{CO}_{2}$. Medium was changed at regular intervals to have good growth of cells and counter the depression of $\mathrm{pH}$.

\section{Transfection of shRNA constructs into CEH cells:}

All the shRNA recombinant plasmid constructs against $S C D$ and $S R E B P 1$ genes were transfected into the chicken primary embryonic hepatocytes in order to assess the activity of shRNA molecules. Approximately $0.4 \mathrm{ml}$ of the hepatocyte cell suspension and plasmid containing shRNA molecules against $S C D$ and SREBP1 genes were taken into electroporation cuvette and mixed gently. Single square wave pulse was given at a voltage of $150 \mathrm{mV}$ for pulse length of 10 milli second. Both, pENTR U6/lacZ shRNA and pcDNA 1.2/V5/lacZ reported plasmids were co-transfected in to CEH. The pcDNA 1.2/V5/lacZ reported plasmid is used as a positive control for RNAi response in CEH. For getting optimal results, we had used 6 fold more entry construct DNA than reporter plasmid during 
co-transfection. Immediately after transfection, approximately $200 \mu \mathrm{l}$ of cell suspension transferred to each well of a well plate containing $1.8 \mathrm{ml}$ of growth medium and incubated at $37^{\circ} \mathrm{C}$ with $5 \% \mathrm{CO}_{2}$ level.

\section{RNA extraction and cDNA synthesis;}

The cells were harvested after 48 hours of transfection and RNA was isolated for transient RNAi analysis. The total RNA was isolated from the hepatic cells grown after successful transfection of the plasmids containing shRNA molecules against both target genes as per the manufacturer's protocol using Trizol (Sigma). The RNA samples were treated with DNase I (Fermentas) for removal of possible genomic DNA contamination. cDNA was synthesized by using HighCapacity cDNA Reverse transcription Kit (Applied Biosystems, \#4368814) in a final volume of $20 \mu \mathrm{L}$ containing 10X Reverse Transcription (RT) buffer (2 $\mu \mathrm{L})$, 10X RT random primers $(2 \mu \mathrm{L}), 100 \mathrm{mM}$ of $25 \mathrm{X}$ dNTP mix $(0.8 \mu \mathrm{L})$, RNase inhibitor $(1 \mu \mathrm{L})$, MultiScribeTM Reverse Transcriptase (1 $\mu \mathrm{L})$, Nuclease-free H2O (3.2 $\mu \mathrm{L})$ and $1 \mathrm{ng}$ RNA $(10 \mu \mathrm{L})$. Reverse transcription was carried out in thermocycler (Mastercycler, Eppendorf, Germany) following the manufacturer's instructions, which includes the incubation of reaction at $25^{\circ} \mathrm{C}$ for 10 minutes followed by $37^{\circ} \mathrm{C}$ for 2 hours and $85^{\circ} \mathrm{C}$ for 5 minutes. The resulted cD NA was stored at $-20^{\circ} \mathrm{C}$ till further use.

\section{Real time quantitative PCR:}

The mRNA expression levels of SCD, SREBP1 genes and immune response genes viz. Interferon-A (IFN-A) and Interferon-B (IFN-B) genes in the transfected hepatic cells were quantified by using thermal cycler Applied Biosystems ${ }^{\circledR}$ Step One Real-Time PCR (Life Technologies) with SYBR ${ }^{\circledR}$ Green JumpStart ${ }^{\text {TM }}$ TaqReadyMix ${ }^{\text {TM }}$. Glyceraldehyde 3-phosphate dehydrogenase (GAPDH) was used as an internal control for normalizing different amounts of input RNA (Table.2). The realtime PCR was performed for each sample in duplicates. Amplification curves for both the target genes showed typical initiation phase, exponential and plateau phase, indicating the successful exponential amplification of the product (Figure.S2). Melt curves of the amplified products displayed specific single peak for SCD, SREBP1 and GAPDH genes, indicating specific amplification and homogeneity of the PCR products. These products were run on $1.5 \%$ agarose gel and expected amplicons sizes were observed.

The gene quantification was expressed as "n-fold up/down regulation of transcription" in relation to a reference sample, called the calibrator (mock transfected hepatocytes). The expression of target gene was calibrated by that of the reference gene, GAPDH, at each time point and converted to the relative expression (fold of expression), as follows:

Fold of expression $=2^{-\Delta \Delta C t}$

Where,

$\triangle \mathrm{Ct}=$ Average $\mathrm{Ct}$ of target gene - Average $\mathrm{Ct}$ of reference gene $(G A P D H)$

$\Delta \Delta \mathrm{Ct}=$ Average $\Delta \mathrm{Ct}$ of target (shRNA) - Average $\Delta \mathrm{Ct}$ of calibrator sample (Mock)

The Knock down efficiency (KD\%) of all the shRNA was calculated by considering scrambled shRNA as control.

\section{Western Blotting for detection of SCD and SREBP1 in cell culture:}

For Western blotting, polyclonal antibodies against SCD and SREBP1 were prepared for which a 591 bp length of SCD cDNA and a 507 bp length of SREBP1 cDNA were amplified by designing specific primers (SCD_Ab Forward: AAGCTTATGCACCACCATCACCATCATAATATCCTCATGAGCCTG; SCD_Ab Reverse: GGATCCAAACATGTGAGCGCTG; SREBP1_Ab Forward: AAGCTTATGCACCACCATCACCATCATCCTGACAGCACCGTGTC; SREBP1_Ab Reverse: GGATCCGTCTGCCTTGATGAAGTG). The forward primers of bothe cDNAs contained with $6 \mathrm{X}$ histidine tag and BamH/ restriction enzyme while the reverse primers contained Hind II/ restriction enzyme. The PCR amplification was carried out in $200 \mu \mathrm{L}$ PCR tubes containing $2.5 \mu \mathrm{L}$ of $10 \mathrm{X}$ buffer, $1 \mu \mathrm{L}$ of dNTP mix $(2.5 \mathrm{mM}), 1.5 \mu \mathrm{L}$ (30ng) each of forward and reverse primers, $0.3 \mu \mathrm{L}(1.5 \mathrm{U})$ of Taq DNA polymerase, $1 \mu \mathrm{L}$ of genomic DNA and nuclease free water to make up the volume up to $25 \mu \mathrm{L}$. Thermal cycling conditions followed for both the genes were initial denaturation at $95^{\circ} \mathrm{C}$ for 10 minutes followed by 35 cycles of denaturation at $95^{\circ} \mathrm{C}$ for 30 seconds, primer annealing at $55^{\circ} \mathrm{C}$ for 30 seconds and extension at $72^{\circ} \mathrm{C}$ for 1 minute 30 sec and a final extension of $72{ }^{\circ} \mathrm{C}$ for 10 minutes. The amplified product was gel eluted and purified by using QIA quick gel extraction kit (Qiagen).

The pAcGFP1-C1 expression vector and purified amplicons of cDNA of both the genes were digested with BamHI and Hind III restriction enzymes. After RE digestion, CDNA of SCD gene and SREBP1 gene were cloned separately into the PAcGFP1-C1 expression vector. The ligated products were transformed into DH5a E. coli competent cells. The positive clones were screened and identified by colony PCR, plasmid PCR and sequencing. The recombinant plasmids were isolated by using Gene JET plasmid miniprep kit (Thermo Scientific, USA). The recombinant plasmids of SCD and SREBP1 genes were transfected into the $\mathrm{CEH}$ by using the Gene Pulser Xcell ${ }^{\mathrm{TM}}$ Electroporation system (Biorad). After transfection, hepatocytes were grown in growth medium for 48 hrs and then, harvested for isolation of proteins. From the cell lysates, both $S C D$ and SREBP1 proteins tagged with 6x histidine were extracted by using the His-Spin Protein Miniprep ${ }^{\mathrm{TM}}$ kit (GCC Biotech, Kolkata, India).

The purified protein was mixed with Freund's Adjuvant (IFA) and the mixture was injected subcutaneously (s/c). Primary injection was given wit Freund's Complete Adjuvant (CFA) and then, booster injections were given with Incomplete Freund's Adjuvant (IFA). A total of 6 male Wistar rats (2 for SCD protein, 2 for SREBP1 protein and 2 as control) of 8 weeks age were included in immunization schedule throughout period. The detailed Immunization protocol for rat polyclonal antibody production was as shown in Table S1. The IgG was purified from hyper immune sera using IgG purification kit (Himedia).

A period of $48 \mathrm{~h}$ after transfection of chicken embryonic hepatocyte cells with shRNAs against $S C D$ and $S R E B P 1$ genes, cell pallets were harvested. The cell pellets were washed in ice cold PBS solution and then cell lysate was prepared by adding cold cell lysis buffer (150 mMNaCl, $1 \% \mathrm{NP}-40$, and $50 \mathrm{mM}$ Tris, $\mathrm{pH}$

Page $4 / 16$ 
7.4) @ $1 \mathrm{ml}$ per $150 \mathrm{~cm}^{2}$ flask, agitated constantly and centrifuged at a rate of $12,000 \mathrm{rpm}$, at $4{ }^{\circ} \mathrm{C}$ for $20 \mathrm{~min}$. Equal volume of Laemmli $2 \mathrm{X}$ sample loading buffer ( $10 \%$ SDS, $0.025 \%$ Bromophenol blue and 1\% DTT) added to the obtained cell lysate and boiled at $100{ }^{\circ} \mathrm{C}$ for $3 \mathrm{~min}$. About $20 \mu \mathrm{l}$ of digested samples containing approximately $15-20 \mu \mathrm{g}$ of protein loaded into the wells of SDS-PAGE with discontinuous buffer system Tris-Glycine-SDS buffer, pH 8.3 to separate the protein mixture. After completion of electrophoresis, the gel containing protein was transferred on to the polyvinylidene fluoride (PVDF) membrane in the presence of Tris-Glycine-Methanol Buffer. After careful transfer of the gel, the blotted PVDF was immersed in 3\% BSA blocking buffer with primary antibody (1:1000 dilution in TBST) and incubated at $4^{\circ} \mathrm{C}$ for overnight. Then the membrane was washed three times with the TBS Tween 20 (TBST) for 5 minutes for each wash. After washing, membrane was incubated with anti-rat IgG HRP conjugate (Sigma) diluted to 1:1000 in TBS Tween 20 buffer for 1.5 hours with constant agitation. After washings with the TBS Tween 20 (TBST), the PVDF membrane was incubated in DAB substrate solution for 5-30 minutes until the color development. Soon after the appearance of brown color, substrate solution was drained and the reaction was stopped by adding distilled water.

\section{Sandwich ELISA for quantitation of SCD and SREBP1 in cell culture:}

IgGs specific for SCD and SREBP1 have been pre-coated onto a 96-well plate (12 x 8 Well Strips) and blocked separately. Test samples (cell lysate obtained after transfecting the shRNA molecules into the hepatocytes) were added to the wells, incubated and removed. HRP detector antibodies specific for $S C D$ and SREBP1 were added, incubated and followed by washing. HRP-Peroxidase Conjugate was then added, incubated and unbound conjugate was washed away. An enzymatic reaction was produced through the addition of TMB substrate which is catalyzed by HRP generating a blue color product that changes yellow after adding acidic stop solution. The density of yellow coloration read by absorbance at $450 \mathrm{~nm}$ is quantitatively proportional to the amount of sample $S C D$ and SREBP1 captured in well.

\section{Statistical analysis:}

The statistical analysis in the experiments was carried out using trial version of SPSS 20. Univariate General linear model with Tukey's HSD and DMRT as post-hoc test was used to study the significant difference between different shRNA groups due to the knock down effect of target genes. Data from representative experiments were presented as Mean \pm SE for different samples with differences determined by least significant differences at $5 \%$ level $(P<$ 0.05). The degree of association between the expression of different genes was calculated by Pearson correlation coefficient.

\section{Results}

\section{shRNA molecules:}

A total of 5shRNA molecules for each of SCD and SREBP1 genes were designed and synthesized. Local secondary structures of target mRNA sequences of $S C D$ and SREBP1 genes were predicted and they revealed that all the all the shRNA target mRNAs consist of stem and loop secondary structures (Figure.1 and Figure.2). Analysis of secondary structures of shRNA molecules designed against SCD and SREBBP1 genes revealed different types of secondary structures (Figure.3 and Figure.4).

The predicted values (negative) of $\triangle \mathrm{G}$ overall, $\triangle \mathrm{G}$ duplex and $\triangle \mathrm{G}$ break-target (disruption energy) for mRNA target regions of SCD and SREBP1 genes were within the desirable range (Table 3 \& Table 4). In case of $S C D$ gene target mRNA region, overall $\triangle G$ value was almost same for shRNA2, shRNA4 and shRNA5. $\triangle G$ duplex value was the highest for shRNA5 and lowest for shRNA1. $\triangle G$ break-target (disruption energy) was highest for shRNA3, lowest for shRNA2. For SREBP1 gene mRNA target regions, overall $\triangle \mathrm{G}$ value was highest for shRNA1, lowest for shRNA2. $\triangle \mathrm{G}$ duplex value was highest for shRNA4 and lowest for shRNA1. $\triangle$ G break-target (disruption energy) was highest for shRNA2 and lowest for shRNA1. GC content of the shRNA target mRNA regions of SCD gene ranged from $43 \%$ to $52 \%$, whereas, GC content of the shRNA target mRNA regions of SREBP1 gene ranged from $48 \%$ to $52 \%$ (Table $3 \&$ Table 4 ).

A volume of $5 \mu \mathrm{l}$ of $500 \mathrm{nM}$ stock of ds oligos from each of the shRNA molecule was loaded on to the $4 \%$ agarose gel for checking the integrity of the annealed ds oligos (Figure.S3 \& Figure.S4). Annealed ds oligos were observed at 50 bp length, unannealed single-stranded oligos were observed at 25 bp length as the agarose gel is non-denaturing. Therefore, the single-stranded oligos do not resolve at the expected size due to formation of secondary structure. Successfully annealed ds oligos were used further for cloning into the pENTR /U6 Entry Vector.

\section{RNAi cassettes for production of shRNAs:}

Successfully annealed ds oligos were used for cloning into RNAi-Ready pENTR/U6 entry vector. After successful ligation of annealed ds oligos into RNAiReady pENTR/U6 entry vector, recombinant clones were transformed into competent $E$. coli cells. Recombinant clones were confirmed by colony PCR (Figure.S5 \& Figure.S6) and plasmid PCR (Figure.S7 \& Figure.S8) on $1.5 \%$ agarose gel and sequencing.

\section{Transient transfection of anti-SCD and -SREBP1 shRNA construct into CEH:}

The hepatocytes were transfected with anti-SCD and -SREBP1 shRNA constructs separately and grown in DMEM medium. The cells were harvested and then, total RNA and DNA were isolated from the harvested hepatocytes. For confirmation of successful transfection of recombinant shRNA molecules, DNA extracted from the harvested hepatocytes was used as template for performing the PCR with specific primers for U6 Entry vector. The PCR products found at a product length of $287 \mathrm{bp}$ confirmed the successful transfection of the recombinant shRNA constructs into the hepatocytes (Figure.S9 \& Figure.S10). The total RNA isolated from the hepatocytes into which recombinant shRNA constructs were transfected, was used for the synthesis of first strand of cDNA. The cDNA was used for performing Real time PCR for assessing the expression of SCD, SREBP1and GAPDH genes in the hepatocytes after transfecting with recombinant shRNA constructs. 


\section{Silencing efficiency of anti-SCD and -SREBP1 shRNA constructs}

A significant $(P<0.05)$ reduction was observed at the mRNA expression levels of $S C D$ and $S R E B P 1$ genes, after transfecting the recombinant shRNA constructs into the hepatocytes, when compared with mock control. Expression levels (40- $\triangle C \mathrm{Ct}$ ) of $S C D$ gene after transfecting with different shRNA constructs was 37.97 , $37.61,38.76,38.42,39.235$ and 39.565 in the cells with shRNA1, shRNA2, shRNA3, shRNA4, shRNA5 and mock control, respectively. Expression of SCD gene in the transfected hepatocytes with shRNA1 and shRNA2 molecules reduced significantly $(P<0.05)$ when compared with the mock control. Knock down efficiency of shRNA1, shRNA2, shRNA3, shRNA4 and shRNA5 molecules were $66.90 \%, 74.21 \%, 42.76 \%, 54.78 \%$ and $20.45 \%$, respectively (Figure.9). The shRNA2 molecule was found as the best molecule among all the shRNA molecules used for silencing the SCD gene expression in vitro.

In case of SREBP1 gene, mRNA expression levels (40- $\triangle \mathrm{Ct}$ ) were 29.58, 33.60, 32.31, 33.72, 33.64 and 34.165 after transfecting with shRNA1, shRNA2, shRNA3, shRNA4, shRNA5 molecules into embryonic hepatocytes and mock control respectively. Expression levels of SREBP1 gene in hepatocytes into which shRNA1, shRNA2, shRNA3 shRNA4 and shRNA5 molecules were transfected, reduced significantly $(\mathrm{P}<0.05)$ when compared with mock control. Knock down efficiency of shRNA1, shRNA2, shRNA3, shRNA4 and shRNA5 molecules were $95.85 \%, 32.64 \%, 72.36 \%, 26.80 \%$ and $30.50 \%$ respectively (Figure 10 ). The shRNA1 molecule was found as the best among all the shRNA molecules used for silencing the SREBP1 gene under cell culture system. However, Western blot analysis also revealed the expression of $S C D$ and SREBP1 proteins in both transfected as well as non-transfected mock control (Figure 5 and Figure 6 ).

\section{Relative quantification of immune response genes in transfected hepatic cells}

The relative expression of immune response genes (IFNA and INFB) was monitored by quantitative PCR, after transfecting the anti-SCD and anti-SREBP1 shRNA constructs into the hepatocytes. Gene expression levels of IFNA (40- $\triangle \mathrm{Ct}$ ) was $38.525,37.93,37.355,36.57,41.23$ and 34.015 , while that of IFNB was $36.385,35.61,34.755,34.815,39.64$ and 33.04 in anti-SCD shRNA constructs viz. shRNA1, shRNA2, shRNA3, shRNA4, shRNA5 and Scrambled shRNA, respectively (Figure 7). In case of anti-SREBP1 shRNA constructs, the mRNA levels of IFNA were 35.44, 39.075, 40.2, 39.615, 40.115 and 38.23 while that of IFNB was $34.28,37.5,38.55,38.185,38.42$ and 37.35 in the hepatocyte cells transfected with shRNA1, shRNA2, shRNA3, shRNA4, shRNA5 and Scrambled shRNA, respectively (Figure 8). There was no significant $(P<0.05)$ difference noticed in the expression of immune response genes when compared between shRNA transfected cells with the scrambled shRNA.

\section{Detection of SCD and SREBP1 protein in cell culture:}

The sandwich ELISA results revealed that, the colour reaction was observed at a titre of 1:250,1:100,1:500,1:500,1:750 and 1:1000 in transfected cells with anti-SCD shRNA1, shRNA2, shRNA3, shRNA4, shRNA5 and scrambled shRNA (Figure 9). In case of anti-SREBP1 shRNA1, shRNA2, shRNA3, shRNA4, shRNA5 and scrambled shRNA, the titre was 1:10, 1:500, 1:100, 1:500, 1:500 and 1:1000, respectively (Figure 10). As shRNA molecules efficiently reduced the production of $S C D$ and SREBP1 protein synthesis, those molecules which have the higher knock down efficiency (shRNA2 for SCD; shRNA1 and for SREBP1) exhibited colour reaction at lower dilutions of protein.

\section{Discussion}

RNA interference (RNAi) has become one of the powerful tools in recent times to suppress the expression of specific gene of interest [17-18], as a therapeutic option in disease management [19-22], as cancer treatment [23-25] and for understanding regulatory function of a gene by dsRNA molecules [26]. Suppression of gene expression achieved by cleavage of dsRNA molecules by ribonuclease protein (Dicer) followed by loading of siRNA molecules into RISC (RNA induced silencing complex) and then, guide strand of the siRNA molecule would guide the RISC towards the target mRNA sequence complementary with the siRNA for cleavage of target mRNA [27-31]. For successful reduction of gene expression through RNAi, designing of shRNA molecules against target gene plays crucial role [32]. In our study, anti shRNA molecules against SCD and SREBP1 genes were synthesized following the criteria such as moderate to low GC content, low internal stability of sense strand at 3' end (at least 3 bases of A/U at 15-19 positions of sense strand) and lack of internal repeats [33]. Basic Local Alignment Search Tool (BLAST) was used to detect whether our designed shRNA molecules are having the homology with any other genes to avoid the potential off-target effects.

Earlier studies revealed that the formation of secondary structures in the anti-sense/guide strand of shRNA molecule had critical role in determining the silencing efficiency and stated that a strong inverse correlation was observed between the degree of formation guide-RNA secondary structure formation and gene silencing efficiency of shRNA [34]. Patzel et al. 2005 classified and reported the secondary structures of guide strands of shRNA as: best silencing exhibited by sequences without any secondary structures, second best were stem loop structures with $\geq 2$ free nucleotides at $5^{\prime}$ and $\geq 4$ free nucleotides at $3^{\prime}$ end, next best were sequences having internal loop and two stem loop structures followed by stem loop structures with short free ends [34]. In accordance with the previous findings in our study, the shRNA molecules with best silencing efficiency (i,e shRNA2 molecule for SCD gene and shRNA1 molecule for SREBP1 gene) did not posses any secondary structure in their anti-sense/guide strands. Second best shRNA molecules (i.e shRNA1 molecule for SCD gene and shRNA3 molecule for SREBP1 gene) have loop structures with $\geq 2$ free nucleotides at $5^{\prime}$ and $\geq 4$ free nucleotides at 3 ' end. Some of the previous studies in chicken also reported that shRNA molecules having no secondary structures in their anti-sense/guide strand had expressed high knock down efficiency in other genes such as myostatin gene and ActRIIB gene [35-36, 32].

Earlier studies suggested that the local structure of mRNA is one of the key factors and had a strong effect on the silencing efficiency of the shRNA molecule [37-42]. All the mRNA target regions of anti-SCD and anti-SREBP1 shRNA molecules revealed stem loop structures. Some studies inferred that presence of loop structures in the target mRNA regions provide easy access to the guide strand to bind with target region and had positive correlation with gene silencing efficiency $[41,43]$. Presence of paired nucleotides and hairpins in the secondary structure of target mRNA region likely to have negative effect on shRNA silencing $[39,41]$. In our study even though all target mRNA regions of $S C D$ and $S R E B P 1$ genes have accessibility, the differences in the silencing efficiency might be because of other responsible factor. 
GC content of the target mRNA region have the crucial role in determining the silencing efficiency and it influences the loading of shRNA molecule into RISC and target affinity and specificity [16]. A high GC content in shRNA molecule hinders the dissociation of siRNA duplex inhibiting RISC loading [44-45]. In contrary to that, some reports stated that a low GC content may reduce silencing efficiency by low target affinity and specificity [46]. The GC content of target mRNA region of our target genes ranged from $43-52 \%$. Previous studies also suggested that GC content between $30 \%$ and $55 \%$ had positive correlation with silencing $[33,47,48]$.

The shRNA molecules possessing high knock down efficiency must have higher negative value of $\Delta \mathrm{G}$ overall, $\Delta \mathrm{G}$ duplex and lesser negative value of $\Delta \mathrm{G}$ break-target (disruption energy) $[18,32]$. Some studies postulated that shRNA molecules having the values of $\Delta \mathrm{G}$ overall, $\Delta \mathrm{G}$ duplex and $\Delta \mathrm{G}$ break-target (disruption energy) within the range of -25 to $-35 \mathrm{kcal} / \mathrm{mol},-30$ to $-40 \mathrm{kcal} / \mathrm{mol}$ and -0.5 to $-1.5 \mathrm{kcal} / \mathrm{mol}$ exhibited good silencing efficiency [32, 49$]$. In our study, all the shRNA molecules designed against $S C D$ and SREBP1 mRNA possessing the values of $\triangle \mathrm{G}$ overall, $\triangle \mathrm{G}$ duplex and $\triangle \mathrm{G}$ break-target (disruption energy) within the desirable range have shown good silencing efficiency. The shRNA2 molecule found as the best in silencing the expression of $S C D$ mRNA having higher negative value of $\triangle \mathrm{G}$ overall, $\triangle \mathrm{G}$ duplex and lesser negative value of $\triangle \mathrm{G}$ break-target (disruption energy) among all shRNAs designed. Similar findings were observed in case of shRNA1 molecule, which was found as the best one in silencing the expression of SREBP1 gene expression. Possessing the thermodynamic properties within the desirable range might be the one of the reasons for better silencing efficiency of shRNA2 in SCD and shRNA1 in SREBP1 genes.

Silencing of the genes which are involved in the fatty acid biosynthesis has benefits like production of lean meat and egg and reduction of fat deposition in several organs of the birds. Silencing of target genes which are involved in the fat biosynthesis by using RNA interference in chicken primary hepatocyte culture helped in the devising suitable in vitro models for knock down of the target gene. This technique can be used further for production of the knock down chicken with reduced fat production. Till date, there were no reports available in the literature regarding the silencing of fatty acid synthesis genes in chicken. In the present study, the shRNA molecules were successfully transfected into the chicken hepatic cells and significant down regulation of the target genes were observed. These results suggest that the chicken embryo hepatocytes can be used for in vitro model for various functional studies. Significant reduction in the expression of $S C D$ and SREBP1 genes in hepatocytes was observed after transfecting the shRNA molecules into them. The shRNA constructs against $S C D$ gene showed the knock down efficiency ranged from 20.4-74.2\%. In case of shRNA constructs against SREBP1 gene, they showed knock down efficiency ranging from $26.8-95.8 \%$. The reasons behind the high knock down efficiency of shRNA2 against SCD gene and shRNA1 molecule against SREBP1 gene might be lack of secondary structures in their anti-sense/guide strand, desirable GC percentage (43\%-52\%) in sense strand, more accessibility in the target mRNA region i.e stem loop structures in secondary structure of mRNA region and possessing thermodynamic properties falling in desirable range. The expression of the SCD and SREBP1 examined in the cell lysates showed lower expression in the cells transfected with shRNAs indicating the similar trends as of mRNA expression in the cell culture. Thus, these results clearly demonstrated the successful down regulation of the gene expression by designed shRNA molecules against both the target genes under in vitro condition. In previous reports, by using shRNA molecules in Myostatin gene [50], ACTRIIA gene [51] and ACTRIIB gene [32] knock down efficiency of $68 \%, 87 \%$ and $82 \%$ were found respectively in chicken embryo fibroblasts cells. In duck embryo fibroblasts, different shRNA molecules mediated through lenti-virus have down regulated the MSTN gene expression by $61.6,76.9$ and $79.1 \%$, respectively, when compared with control cells [52]. In caprine foetal fibroblasts, mRNA expression levels of myostatin gene were down regulated by $89 \%$ [53] and $72 \%$ [54] after transient transfection of shRNA molecules into them.

RNA interference is powerful technique for down regulating the particular gene but it may cause the activation of immune response genes under in vitro and in vivo condition. According to the recent reports, both immune cells and non-immune cells can detect the shRNA molecules irrespective of their sequence and leads to the stimulation of interferon and inflammatory cytokines under in vivo and in vitro conditions [55, 56]. It was also reported that, shRNA molecules shorter than size of $30 \mathrm{bp}$ can escape the PKR activation. It is known that the IFN response caused by activation of protein kinase R (PKR), ultimately leads to the inhibition of protein synthesis [56]. In the present study, we observed the expression of immune response genes particularly IFNA and IFNB in both tranfected and non-transfected control cells in case of both SCD and SREBP1 experiments. In both the genes, the non-significant differences of expression of IFNA and IFNB genes between shRNA transfecetd cells and either scrambled shRNA transfected cells or un-transfected negative control embryonic hepatocyte cells. In supporting to the results obtained in the present study, Patel et al. (2014) and Guru Vishnu et al. (2019) in ACTIIB gene in goat and chicken fibroblast cells, respectively [57, 32]. We suggest that shRNAs designed in our study against both $S C D$ and $S R E B P 1$ genes had the potential to be excellent shRNA molecules for further development of knock down chicken as the shRNA molecules having very good knock down efficiency escaped the interferon system of the cells.

\section{Conclusion}

It is concluded that short hairpin RNA-based silencing of SCD and SREBP1 genes under in vitro chicken hepatic cell culture system have been developed to minimize expression of these genes. The knock-down efficiency for both the genes reached more than $70 \%$ under in vitro cell culture system without affecting expression of immune response genes.

\section{Declarations}

\section{Acknowledgements}

The authors convey thanks to the Indian Council of Agricultural Research, Govt. of India for financial support to carry out this research work under the National Fellow project awarded to the Corresponding author. The work was the part of the Ph. D thesis work of the first author.

\section{Ethical Approval}

The whole study was approved by the Institute Animal Ethics Committee (IAEC) to carry out the animal experiment. 
Consent to Participate

Not applicable.

\section{Consent to Publish}

Not applicable.

\section{Authors Contributions}

NGS has done wet lab experiment. ARP has done cell culture work. PK has analysed the data. BB has prepared all the tables. PGV has also helped in data analysis. TKB conceived the idea, planned the experiments and prepared the manuscript.

\section{Funding}

The financial support was provided by the Education Division, Indian Council of Agricultural Research, New Delhi, India to carry out this research work under National Fellow project conferred to the corresponding author.

\section{Competing Interests}

The authors declare that they have no competing interests.

\section{Availability of data and materials}

The data and materials that support the findings of this study are available as the supplementary material of this article and in the lab.

\section{References}

1. Havenstein, G. B., Ferket, P. R., \& Qureshi, M. A. (2003). Growth, livability, and feed conversion of 1957 versus 2001 broilers when fed representative 1957 and 2001 broiler diets. Poultry science, $82,1500-1508$

2. Zerehdaran, S. A. L. J., Vereijken, A. J., Van Arendonk, J. A. M., \& Van der Waaijt, E. H. (2004). Estimation of genetic parameters for fat deposition and carcass traits in broilers. Poultry science, $83,521-525$

3. Siegel, P. B., \& Wolford, J. H. (2003). A review of some results of selection for juvenile body weight in chickens. The Journal of Poultry Science, $40,81-91$

4. Hermier, D. (1997). Lipoprotein metabolism and fattening in poultry. The Journal of nutrition, 127, 805-808

5. Whitehead, C. C., \& Griffin, H. D. (1984). Development of divergent lines of lean and fat broilers using plasma very low-density lipoprotein concentration as selection criterion: the first three generations. British Poultry Science, 25, 573-582

6. Griffin, H. D., Guo, K., Windsor, D., \& Butterwith, S. C. (1992). Adipose tissue lipogenesis and fat deposition in leaner broiler chickens. The Journal of nutrition, 122, 363-368

7. Enoch, H. G., Catala, A., \& Strittmatter, P. (1976). Mechanism of rat liver microsomal stearyl-CoA desaturase. Studies of the substrate specificity, enzymesubstrate interactions, and the function of lipid. Journal of Biological Chemistry, 251, 5095-5103

8. Peláez, R., Pariente, A., Pérez-Sala, Ã., \& Larráyoz, I. M. (2020). Sterculic acid: the mechanisms of action beyond stearoyl-CoA desaturase inhibition and therapeutic opportunities in human diseases. Cells, 9, 140

9. Seppälä-Lindroos, A., Vehkavaara, S., Häkkinen, A. M., Goto, T., Westerbacka, J., Sovijärvi, A. ... Yki-Järvinen, H. (2002). Fat accumulation in the liver is associated with defects in insulin suppression of glucose production and serum free fatty acids independent of obesity in normal men. The Journal of Clinical Endocrinology \& Metabolism, 87, 3023-3028

10. Brown, W. R., Hubbard, S. J., Tickle, C., \& Wilson, S. A. (2003). The chicken as a model for large-scale analysis of vertebrate gene function. Nature Reviews Genetics, 4, 87-98

11. Bertolio, R., Napoletano, F., Mano, M., Maurer-Stroh, S., Fantuz, M., Zannini, A. ... Del Sal, G. (2019). Sterol regulatory element binding protein 1 couples mechanical cues and lipid metabolism. Nature communications, 10, 1-11

12. Zuker, M. (2003). Mfold web server for nucleic acid folding and hybridization prediction. Nucleic acids research, 31, 3406-3415

13. Lorenz, R., Bernhart, S. H., Siederdissen, Z., Tafer, C. H., Flamm, H., Stadler, C., \& Hofacker, I. L., P. F., \&. (2011). ViennaRNA Package 2.0. Algorithms for molecular biology, 6, 1-14

14. Mathews, D. H., Burkard, M. E., Freier, S. M., Wyatt, J. R., \& Turner, D. H. (1999). Predicting oligonucleotide affinity to nucleic acid targets. Rna, 5, 14581469

15. Reuter, J. S., \& Mathews, D. H. (2010). RNAstructure: software for RNA secondary structure prediction and analysis. BMC bioinformatics, 11, 1-9

16. Pascut, D., Bedogni, G., \& Tiribelli, C. (2015). Silencing efficacy prediction: a retrospective study on target mRNA features.Bioscience reports, 35.

17. Fire, A., Xu, S., Montgomery, M. K., Kostas, S. A., Driver, S. E., \& Mello, C. C. (1998). Potent and specific genetic interference by double-stranded RNA in Caenorhabditis elegans. nature, 391, 806-811

18. Hannon, G. J. (2002). RNA interference. nature, 418, 244-251

19. Acharya, R. (2019). The recent progresses in shRNA-nanoparticle conjugate as a therapeutic approach. Materials Science and Engineering: C, 104, 109928 
20. Acharya, R. (2020). Prospective vaccination of COVID-19 using shRNA-plasmid-LDH nanoconjugate. Medical Hypotheses, 143,110084

21. Kumar, S., Dey, A., Yau, Y. Y., Easterling, M., \& Sahoo, L. (2020). RNA Interference: For Improving Traits and Disease Management in Plants. In Climate Change, Photosynthesis and Advanced Biofuels (pp. 339-368). Singapore: Springer

22. Thijssen, M. F., Brüggenwirth, I. M., Gillooly, A., Khvorova, A., Kowalik, T. F., \& Martins, P. N. (2019). Gene silencing with siRNA (RNA interference): a new therapeutic option during ex vivo machine liver perfusion preservation. Liver Transplantation, 25, 140-151

23. Ni, Q., Zhang, F., Zhang, Y., Zhu, G., Wang, Z., Teng, Z. ... Chen, X. (2018). In situ shRNA synthesis on DNA-polylactide nanoparticles to treat multidrug resistant breast cancer. Advanced Materials, 30, 1705737

24. Qiao, H., Wang, Y. F., Yuan, W. Z., Zhu, B. D., Jiang, L., \& Guan, Q. L. (2018). Silencing of ENO1 by shRNA inhibits the proliferation of gastric cancer cells. Technology in cancer research \& treatment, 17, 1533033818784411

25. Shailender, G., Patanla, K., \& Malla, R. R. (2020). ShRNA-mediated matrix metalloproteinase-2 gene silencing protects normal cells and sensitizes cancer cells against ionizing-radiation induced damage. Journal of cellular biochemistry, 121, 1332-1352

26. Patel, M., \& Peter, M. E. (2018). Identification of DISE-inducing shRNAs by monitoring cellular responses. Cell Cycle, 17, 506-514

27. Bernstein, E., Caudy, A. A., Hammond, S. M., \& Hannon, G. J. (2001). Role for a bidentate ribonuclease in the initiation step of RNA interference. Nature, 409, 363-366

28. Elbashir, S. M., Harborth, J., Lendeckel, W., Yalcin, A., Weber, K., \& Tuschl, T. (2001). Duplexes of 21-nucleotide RNAs mediate RNA interference in cultured mammalian cells. nature, 411, 494-498

29. Hammond, S. M., Bernstein, E., Beach, D., \& Hannon, G. J. (2000). An RNA-directed nuclease mediates post-transcriptional gene silencing in Drosophila cells. Nature, 404, 293-296

30. Hammond, S. M., Caudy, A. A., \& Hannon, G. J. (2001). Post-transcriptional gene silencing by double-stranded RNA. Nature Reviews Genetics, 2, 110-119

31. Zamore, P. D., Tuschl, T., Sharp, P. A., \& Bartel, D. P. (2000). RNAi: double-stranded RNA directs the ATP-dependent cleavage of mRNA at 21 to 23 nucleotide intervals. Cell, 101, 25-33

32. Vishnu, P. G., Bhattacharya, T. K., Bhushan, B., Kumar, P., Chatterjee, R. N., Paswan, C. ... Prasad, A. R. (2019). In silico prediction of short hairpin RNA and in vitro silencing of activin receptor type IIB in chicken embryo fibroblasts by RNA interference. Molecular biology reports, 46, 2947-2959

33. Reynolds, A., Leake, D., Boese, Q., Scaringe, S., Marshall, W. S., \& Khvorova, A. (2004). Rational siRNA design for RNA interference. Nature biotechnology, $22,326-330$

34. Patzel, V., Rutz, S., Dietrich, I., Köberle, C., Scheffold, A., \& Kaufmann, S. H. (2005). Design of siRNAs producing unstructured guide-RNAs results in improved RNA interference efficiency. Nature biotechnology, 23, 1440-1444

35. Bhattacharya, T. K., Shukla, R., Chatterjee, R. N., \& Dushyanth, K. (2017). Knock down of the myostatin gene by RNA interference increased body weight in chicken. Journal of biotechnology, 241, 61-68

36. Tripathi, A. K., Aparnathi, M. K., Patel, A. K., \& Joshi, C. G. (2013). In vitro silencing of myostatin gene by shRNAs in chicken embryonic myoblast cells. Biotechnology progress, 29, 425-431

37. Bohula, E. A., Salisbury, A. J., Sohail, M., Playford, M. P., Riedemann, J., Southern, E. M., \& Macaulay, V. M. (2003). The efficacy of small interfering RNAs targeted to the type 1 insulin-like growth factor receptor (IGF1R) is influenced by secondary structure in the IGF1R transcript. Journal of Biological chemistry, 278, 15991-15997

38. Gredell, J. A., Berger, A. K., \& Walton, S. P. (2008). Impact of target mRNA structure on siRNA silencing efficiency: a large-scale study. Biotechnology and bioengineering, 100, 744-755

39. Kretschmer-Kazemi Far, R., \& Sczakiel, G. (2003). The activity of siRNA in mammalian cells is related to structural target accessibility: a comparison with antisense oligonucleotides. Nucleic acids research, 31, 4417-4424

40. Luo, K. Q., \& Chang, D. C. (2004). The gene-silencing efficiency of siRNA is strongly dependent on the local structure of mRNA at the targeted region. Biochemical and biophysical research communications, 318, 303-310

41. Schubert, S., Grünweller, A., Erdmann, V. A., \& Kurreck, J. (2005). Local RNA target structure influences siRNA efficacy: systematic analysis of intentionally designed binding regions. Journal of molecular biology, 348, 883-893

42. Stewart, C. K., Li, J., \& Golovan, S. P. (2008). Adverse effects induced by short hairpin RNA expression in porcine fetal fibroblasts. Biochemical and biophysical research communications, 370, 113-117

43. Overhoff, M., Alken, M., Far, R. K. K., Lemaitre, M., Lebleu, B., Sczakiel, G., \& Robbins, I. (2005). Local RNA target structure influences siRNA efficacy: a systematic global analysis. Journal of molecular biology, 348, 871-881

44. Holen, T. (2005). Mechanisms of RNAi: mRNA cleavage fragments may indicate stalled RISC. Journal of RNAi and gene silencing: an international journal of RNA and gene targeting research, 1, 21

45. Matveeva, O., Nechipurenko, Y., Rossi, L., Moore, B., Sætrom, P., Ogurtsov, A. Y. ... Shabalina, S. A. (2007). Comparison of approaches for rational siRNA design leading to a new efficient and transparent method. Nucleic acids research, 35, e63

46. Li, W., \& Cha, L. (2007). Predicting siRNA efficiency. Cellular and molecular life sciences: CMLS, 64, 1785-1792

47. Shah, J. K., Garner, H. R., White, M. A., Shames, D. S., \& Minna, J. D. (2007). sIR: siRNA Information Resource, a web-based tool for siRNA sequence design and analysis and an open access siRNA database. BMC bioinformatics, 8, 1-7

48. Wang, L., \& Mu, F. Y. (2004). A Web-based design center for vector-based siRNA and siRNA cassette. Bioinformatics, 20, 1818-1820 
49. Shao, Y., Chan, C. Y., Maliyekkel, A., Lawrence, C. E., Roninson, I. B., \& Ding, Y. (2007). Effect of target secondary structure on RNAi efficiency. Rna, 13, 1631-1640

50. Tripathi, A. K., Aparnathi, M. K., Vyavahare, S. S., Ramani, U. V., Rank, D. N., \& Joshi, C. G. (2012). Myostatin gene silencing by RNA interference in chicken embryo fibroblast cells. Journal of biotechnology, 160, 140-145

51. Satheesh, P., Bhattacharya, T. K., Kumar, P., Chatterjee, R. N., Dhara, S. K., Paswan, C. ... Dushyanth, K. (2016). Gene expression and silencing of activin receptor type 2A (ACVR2A) in myoblast cells of chicken. British poultry science, 57, 763-770

52. Tao, Z., Zhu, C., Song, C., Song, W., Ji, G., Shan, Y. ... Li, H. (2015). Lentivirus-mediated RNA interference of myostatin gene affects MyoD and Myf5 gene expression in duck embryonic myoblasts. British poultry science, 56, 551-558

53. Kumar, R., Singh, S. P., Kumari, P., \& Mitra, A. (2014). Small interfering RNA (siRNA)-mediated knockdown of myostatin influences the expression of myogenic regulatory factors in caprine foetal myoblasts. Applied biochemistry and biotechnology, 172, 1714-1724

54. Jain, S. K., Jain, H., Kumar, D., Bedekar, M. K., Pandey, A. K., \& Sarkhel, B. C. (2015). Quantitative evaluation of myostatin gene in stably transfected caprine fibroblast cells by anti-myostatin shRNA. Applied biochemistry and biotechnology, 177, 486-497

55. Sledz, C. A., Holko, M., De Veer, M. J., Silverman, R. H., \& Williams, B. R. (2003). Activation of the interferon system by short-interfering RNAs. Nature cell biology, 5, 834-839

56. Judge, A. D., Sood, V., Shaw, J. R., Fang, D., McClintock, K., \& MacLachlan, I. (2005). Sequence-dependent stimulation of the mammalian innate immune response by synthetic siRNA. Nature biotechnology, 23, 457-462

57. Patel, A. K., Tripathi, A. K., Shah, R. K., Patel, U. A., \& Joshi, C. G. (2014). Assessment of goat activin receptor type IIB knockdown by short hairpin RNAs in vitro. Journal of Receptors and Signal Transduction, 34, 506-512

\section{Tables}

Table 1. List of designed shRNA molecules against SCD and SREBP1 genes. The shRNA molecules were designed using publicly available sequences at NCBI Accession No. NC_006093 for SCD and NCBI Accession No. NC_006101 for SREBP1 genes.

\begin{tabular}{|ll|}
\hline shRNA ID & Nucleotide sequence (5' to ${ }^{\prime}$ ) \\
\hline Lac Z_top & SCD \\
\hline Lac Z_bottom & AAAACTACACAAATCAGCGATTTTTCGAAATCGCTGATTTGTGTAGC \\
\hline 140_top & CACCGCATGGTAGATGATCTCTTTGCGAAcaaagagatcatctaccatgc \\
\hline 140_bottom & AAAAGCATGGTAGATGATCTCTTTGTTCGCAAAGAGATCATCTACCATGC \\
\hline 201_top & CACCGCGATACGTCTGGAGGAATATCGAAatattcctccagacgtatcgc \\
\hline 201_bottom & AAAAGCGATACGTCTGGAGGAATATTTCGATATTCCTCCAGACGTATCGC \\
\hline 362_top & CACCGGAGCCATCGATCCTACAAAGCGAActttgtaggatcgatggctcc \\
\hline 362_bottom & AAAAGGAGCCATCGATCCTACAAAGTTCGCTTTGTAGGATCGATGGCTCC \\
\hline 496_top & CACCGCAGACCCTCACAATGCTATGCGAAcatagcattgtgagggtctgc \\
\hline 496_bottom & AAAAGCAGACCCTCACAATGCTATGTTCGCATAGCATTGTGAGGGTCTGC \\
\hline 591_top & CACCGCTGGACCTGAGTGATTTAAACGAAtttaaatcactcaggtccagc \\
\hline 591_bottom & AAAAGCTGGACCTGAGTGATTTAAATTCGTTTAAATCACTCAGGTCCAGC \\
\hline & SREBP1 \\
\hline 114_top & CACCGATCAACACACCGGACAATGACGAAtcattgtccggtgtgttgatc \\
\hline 114_bottom & AAAAGATCAACACACCGGACAATGATTCGTCATTGTCCGGTGTGTTGATC \\
\hline 935_top & CACCGCTCATCCATCAACGACAAGACGAAtcttgtcgttgatggatgagc \\
\hline 935_bottom & AAAAGCTCATCCATCAACGACAAGATTCGTCTTGTCGTTGATGGATGAGC \\
\hline 1050_top & CACCGCAGAGCAACCAGAAGCTGAACGAAttcagcttctggttgctctgc \\
\hline 1050_bottom & AAAAGCAGAGCAACCAGAAGCTGAATTCGTTCAGCTTCTGGTTGCTCTGC \\
\hline 1074_top & CACCGGAGAACCTCAGCCTGAAGATCGAAatcttcaggctgaggttctcc \\
\hline 1074_bottom & AAAAGGAGAACCTCAGCCTGAAGATTTCGATCTTCAGGCTGAGGTTCTCC \\
\hline 2430_top & CACCGGATGCGTTGGAGTACCTTCACGAAtgaaggtactccaacgcatcc \\
\hline 2430_bottom & AAAAGGATGCGTTGGAGTACCTTCATTCGTGAAGGTACTCCAACGCATCC \\
\hline
\end{tabular}

Page 10/16 
Bold upper case letters - sense target sequence, Lower case letter - anti sense sequence, Italic letters - Loop

Table 2. List of primers used for real time expression quantification of SCD, SREBP1 and immune response genes

\begin{tabular}{|lllll|}
\hline Gene Symbol & Primer Sequences $\left(\mathbf{5}^{\prime}-\mathbf{3}^{\prime}\right)$ & Amplicon Size $(\mathbf{b p})$ & Annealing Temperature $\left({ }^{\circ} \mathrm{C}\right)$ & Accession Number \\
\hline SCD & F:TGACGCTGATCCCTTCTGC & 152 & 57 & NC_006093 \\
& R:AATAGTCAAGAAGATCCGCAG & & 59 & NC_006101 \\
\hline SREBP1 & F:ACGACATGCTGCAGCTGATC & 160 & & NM_204305 \\
& R: GGGAACACATTGCCGGTAG & & 58 & NM_205427 \\
\hline IFNA & F:CTGCCGTCCTCTCTGGC & 119 & 58 & NM_001024836 \\
\hline IFNB & F: GACAGTGCCCTTGAAGTG & & & \\
\hline
\end{tabular}

Table 3. Thermo Dynamic properties \& knock down efficiencies of anti-SCD shRNA molecules in chicken embryonic hepatic cell culture.

\begin{tabular}{|c|c|c|c|c|c|c|c|c|c|}
\hline \multirow[t]{2}{*}{ S.No } & \multirow[t]{2}{*}{ Molecule } & \multirow[t]{2}{*}{ Target mRNA sequence } & \multirow[t]{2}{*}{ Position on mRNA } & \multirow{2}{*}{$\begin{array}{l}\text { Secondary } \\
\text { structure of } \\
\text { target mRNA }\end{array}$} & \multirow[t]{2}{*}{$\begin{array}{l}\text { Target } \\
\text { Exon }\end{array}$} & \multirow[t]{2}{*}{$\begin{array}{l}\text { GC } \\
\text { Content(\%) }\end{array}$} & \multicolumn{3}{|c|}{$\begin{array}{l}\text { Thermodynamic } \\
\text { Parameters }\end{array}$} \\
\hline & & & & & & & $\begin{array}{l}\text { Overall } \\
\Delta G\end{array}$ & $\begin{array}{l}\text { Duplex } \\
\Delta G\end{array}$ & $\begin{array}{l}E \\
t \\
L\end{array}$ \\
\hline 1 & shRNA1 & GCATGGTAGATGATCTCTTTG & $140-160$ & Stem+Loop & 2 & 43 & -28 & -32 & $\therefore$ \\
\hline 2 & shRNA2 & GCGATACGTCTGGAGGAATAT & $201-221$ & Stem+Loop & 2 & 48 & -30.7 & -32.8 & -1 \\
\hline 3 & shRNA3 & GGAGCCATCGATCCTACAAAG & $362-382$ & Stem+Loop & 3 & 52 & -28.2 & -33.3 & $\therefore$ \\
\hline 4 & shRNA4 & GCAGACCCTCACAATGCTATG & $496-516$ & $\begin{array}{l}\text { Stem+ Large } \\
\text { Loop }\end{array}$ & 4 & 52 & -30.6 & -33.7 & - \\
\hline 5 & shRNA5 & GCTGGACCTGAGTGATTTAAA & $591-611$ & Stem+ 2 Loops & 5 & 43 & -30.8 & -33.8 & -1 \\
\hline
\end{tabular}

Table 4. Thermo Dynamic properties \& knock down efficiencies of anti-SREBP1 shRNA molecules in chicken embryonic hepatic cell culture.

\begin{tabular}{|c|c|c|c|c|c|c|c|c|c|}
\hline \multirow[t]{2}{*}{ S.No } & \multirow[t]{2}{*}{ Molecule } & \multirow[t]{2}{*}{ Target mRNA sequence } & \multirow[t]{2}{*}{$\begin{array}{l}\text { Position on } \\
\text { mRNA }\end{array}$} & \multirow{2}{*}{$\begin{array}{l}\text { Secondary } \\
\text { structure of } \\
\text { target } \\
\text { mRNA }\end{array}$} & \multirow[t]{2}{*}{$\begin{array}{l}\text { Target } \\
\text { Exon }\end{array}$} & \multirow[t]{2}{*}{$\begin{array}{l}\text { GC } \\
\text { Content(\%) }\end{array}$} & \multicolumn{3}{|c|}{$\begin{array}{l}\text { Thermodynamic } \\
\text { Parameters }\end{array}$} \\
\hline & & & & & & & $\begin{array}{l}\text { Overall } \\
\Delta G\end{array}$ & $\begin{array}{l}\text { Duplex } \\
\Delta G\end{array}$ & $\begin{array}{l}E \\
\mathrm{t} \\
L\end{array}$ \\
\hline 1 & shRNA1 & GATCAACACACCGGACAATGA & $114-134$ & Stem+Loop & 2 & 48 & -30 & -32.8 & -1 \\
\hline 2 & shRNA2 & GCTCATCCATCAACGACAAGA & $935-955$ & $\begin{array}{l}\text { Stem+ } \\
\text { Loops }\end{array}$ & 6 & 48 & -24.1 & -33 & $-\because$ \\
\hline 3 & shRNA3 & GCAGAGCAACCAGAAGCTGAA & $1050-1070$ & Stem+Loop & 7 & 52 & -27.4 & -33.9 & $\therefore$ \\
\hline 4 & shRNA4 & GGAGAACCTCAGCCTGAAGAT & 1074-1094 & Stem+Loop & 7 & 52 & -25.9 & -34.3 & $\therefore$ \\
\hline 5 & shRNA5 & GGATGCGTTGGAGTACCTTCA & $2430-2450$ & Stem+Loop & 15 & 52 & -24.2 & -33.6 & $\therefore$ \\
\hline
\end{tabular}

\section{Figures}



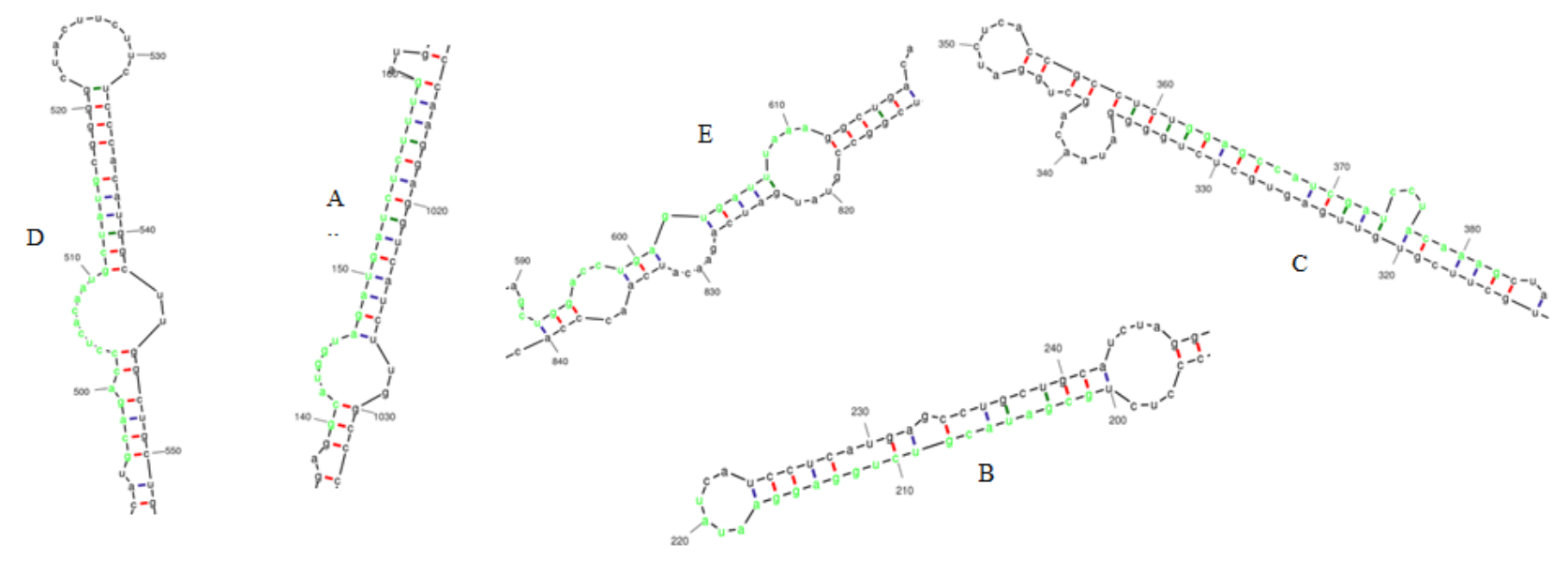

Figure 1

Local secondary structures of SCD mRNA targeted by shRNA1 - A, shRNA2 - B, shRNA3 - C, shRNA4 - D and shRNA5 - E. Bold and under lined regions mRNA region targeted by shRNA.
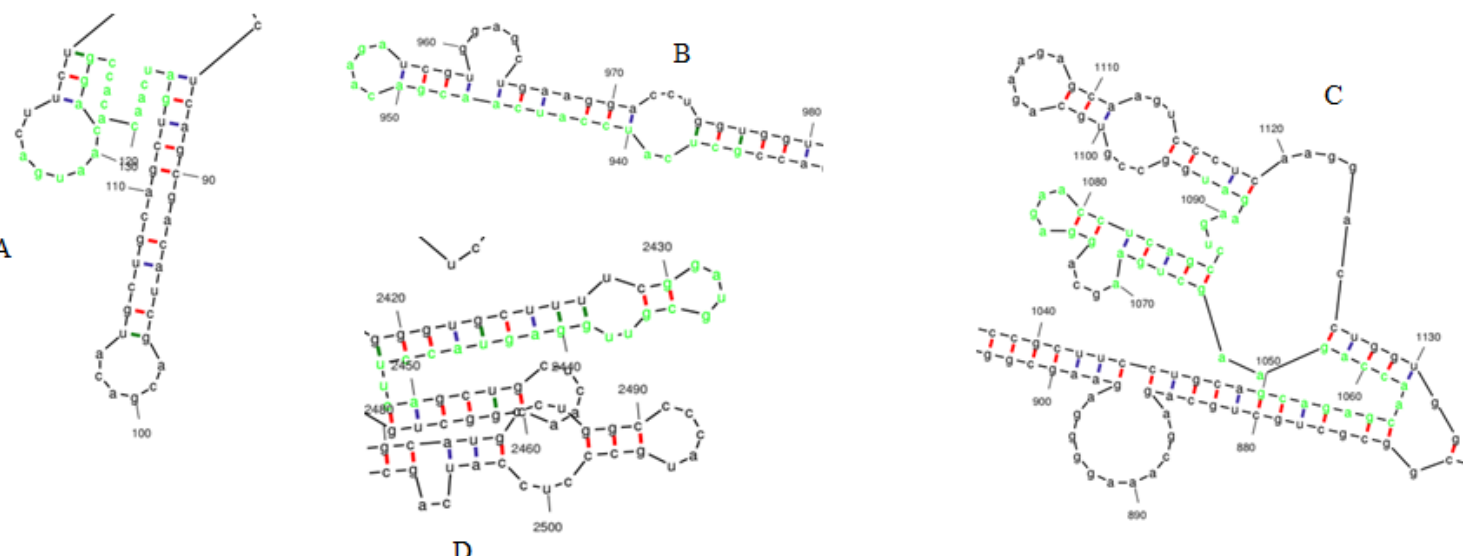

Figure 2

Local secondary structures of SREBP1 mRNA targeted by shRNA1 - A, shRNA2 - B, shRNA3 \& shRNA4 - C and shRNA5 - D. Bold and under lined regions mRNA region targeted by shRNA.

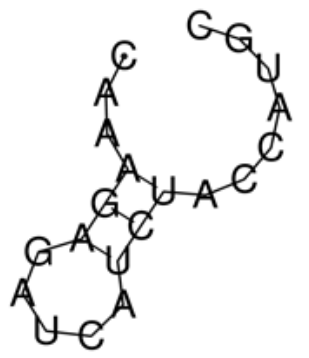

shRNA1

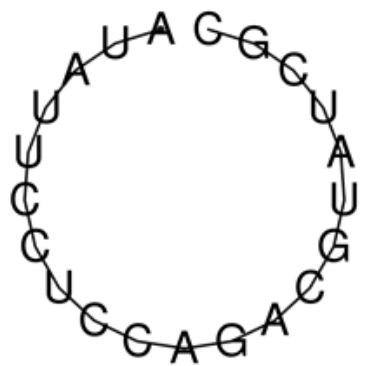

shRNA2

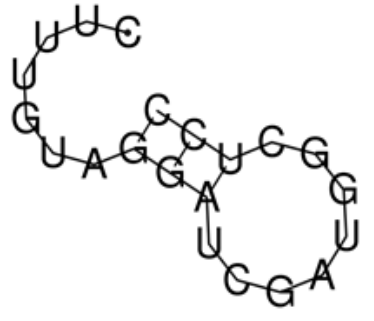

shRNA3

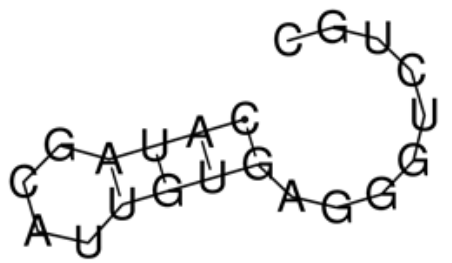

shRNA4

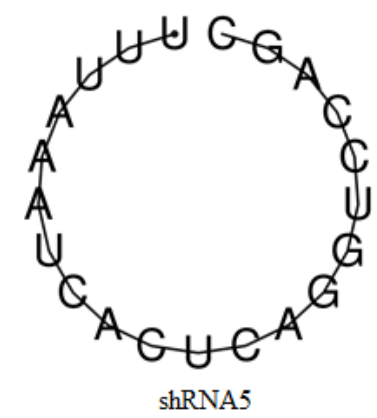

Page 12/16 
Figure 3

Secondary structures of anti sense/guide strand of different shRNA molecules designed against SCD mRNA.

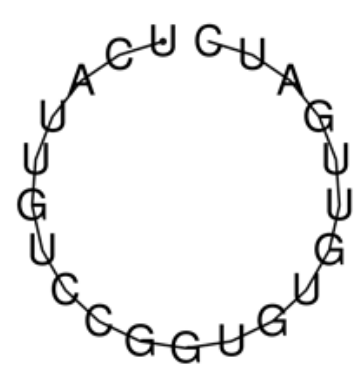

shRNA1

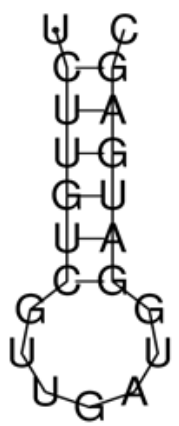

ShRNA2

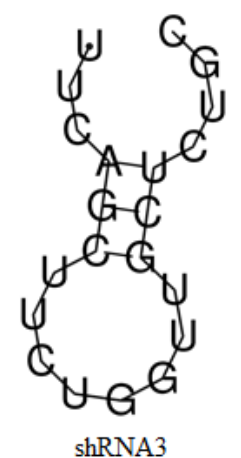

shRNA3
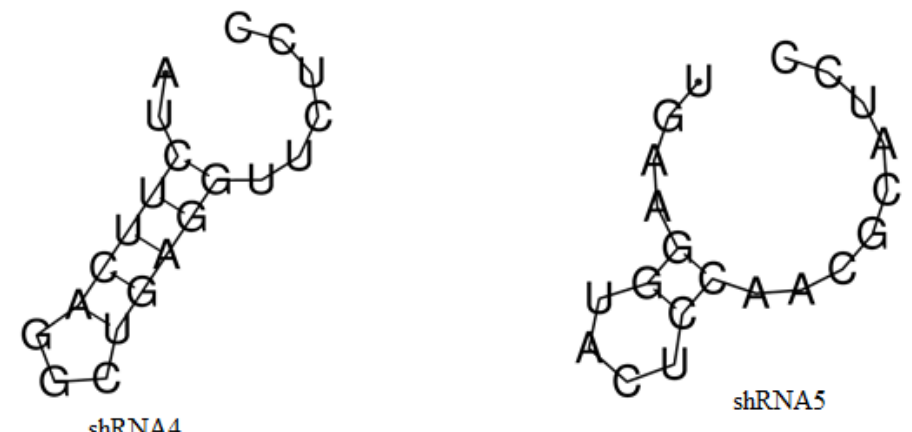

\section{Figure 4}

Secondary structures of anti sense/guide strand of different shRNA molecules designed against SREBP1 mRNA.

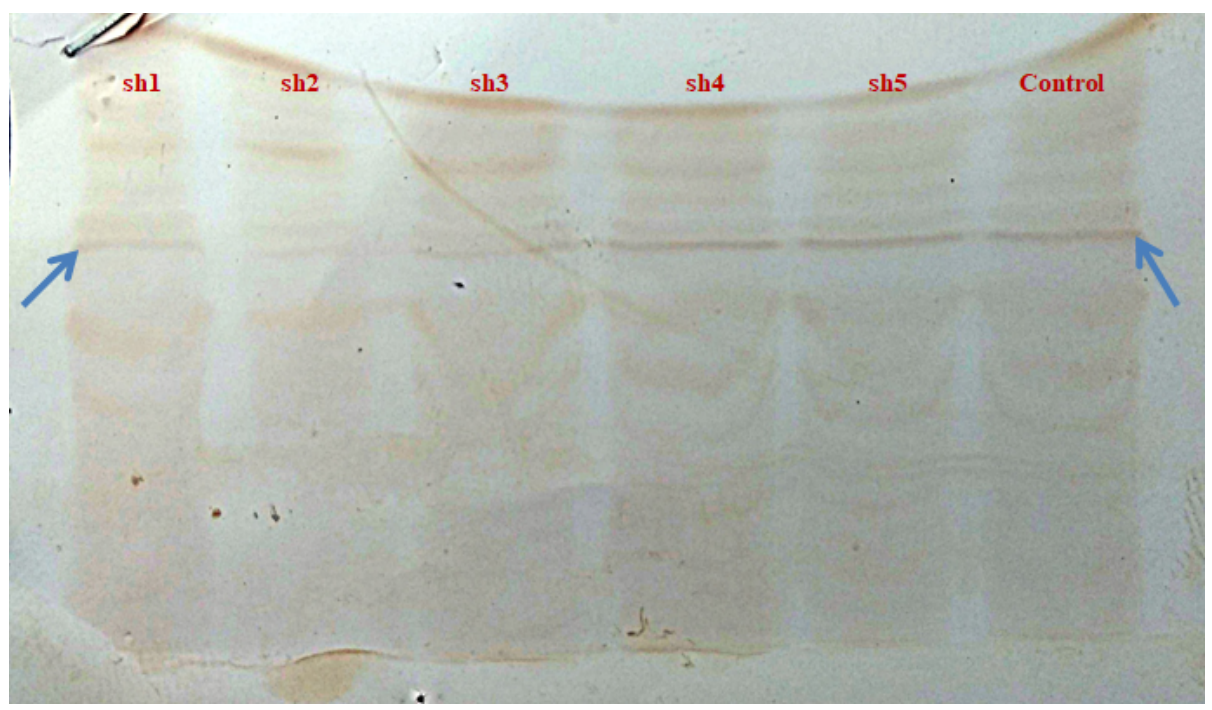

Figure 5

Western blot analysis of SCD expression in transfected chicken embryo hepatocytes. Lane sh1: shRNA1 transfected cells, Lane sh2: shRNA2 transfected cells, Lane sh3: shRNA3 transfected cells, Lane sh4: shRNA4 transfected cells, Lane sh5: shRNA5 transfected cells. Arrow indicates presence of blot of SCD protein in cell culture. 


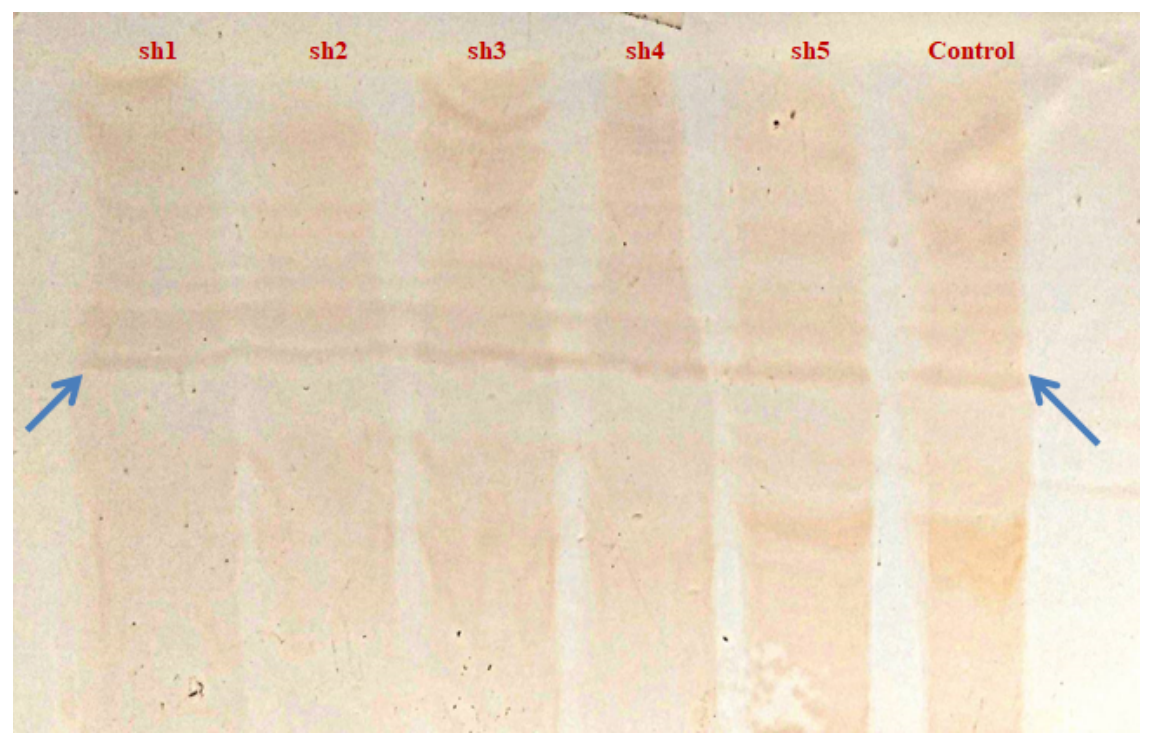

\section{Figure 6}

Western blot analysis of SREBP1 expression in transfected chicken embryo hepatocytes. Lane sh1: shRNA1 transfected cells, Lane sh2: shRNA2 transfected cells, Lane sh3: shRNA3 transfected cells, Lane sh4: shRNA4 transfected cells, Lane sh5: shRNA5 transfected cells. Arrow indicates presence of blot of SREBP1 protein in cell culture.

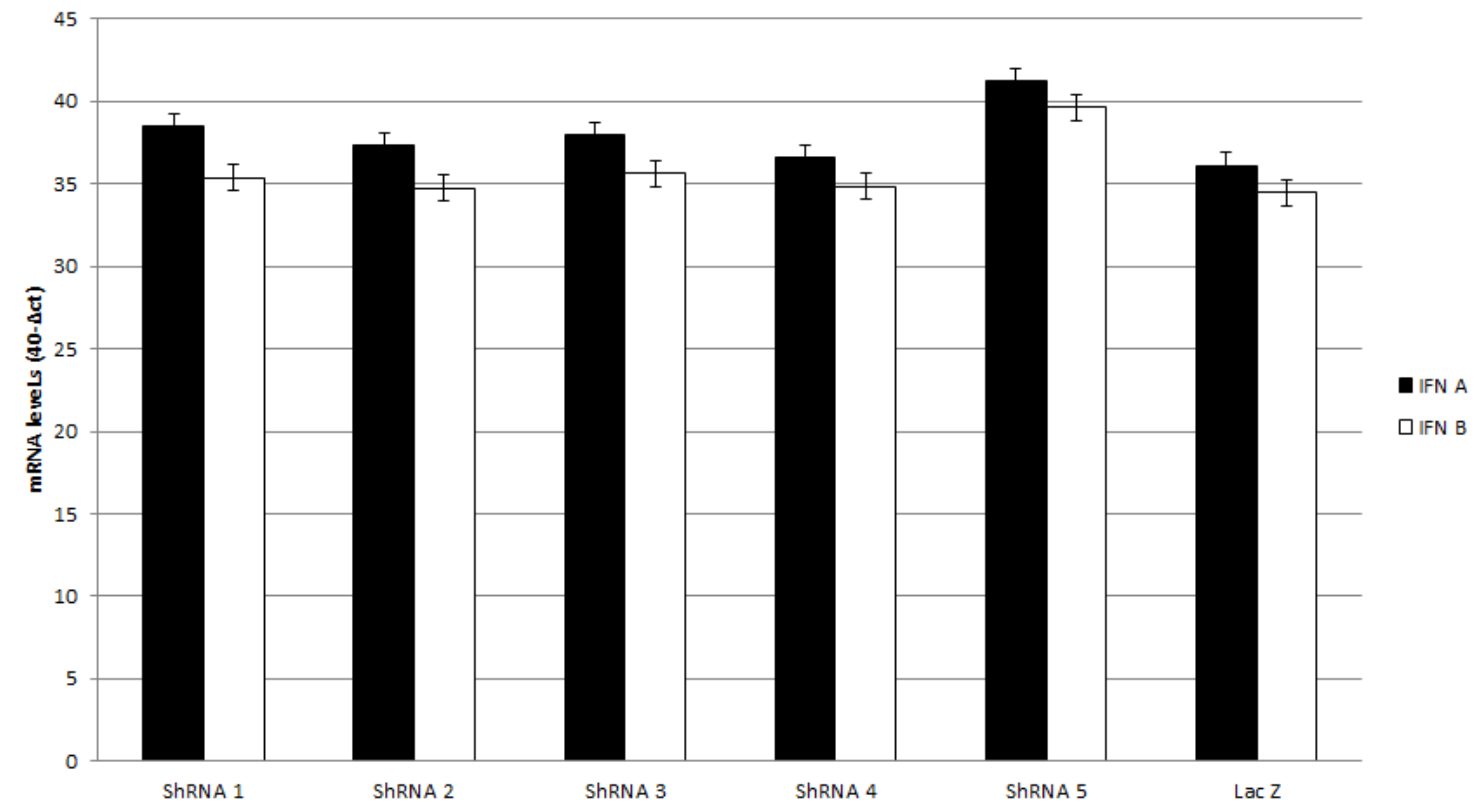

Figure 7

Expression of immune response genes (IFNA and IFNB) in hepatocytes transfected with anti-SCD shRNA constructs. 


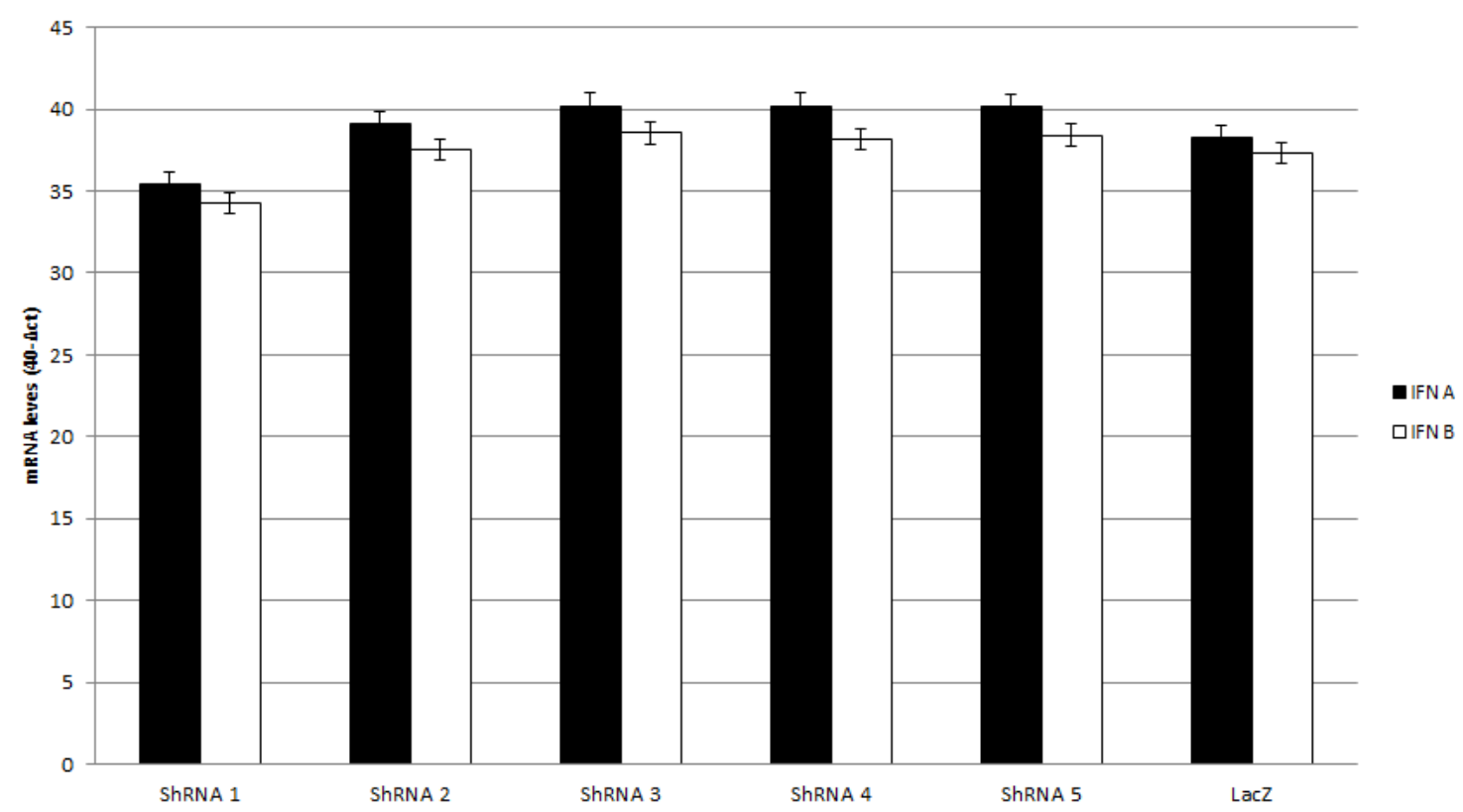

Figure 8

Expression of immune response genes (IFNA and IFNB) in hepatocytes transfected with anti-SREBP1 shRNA constructs.

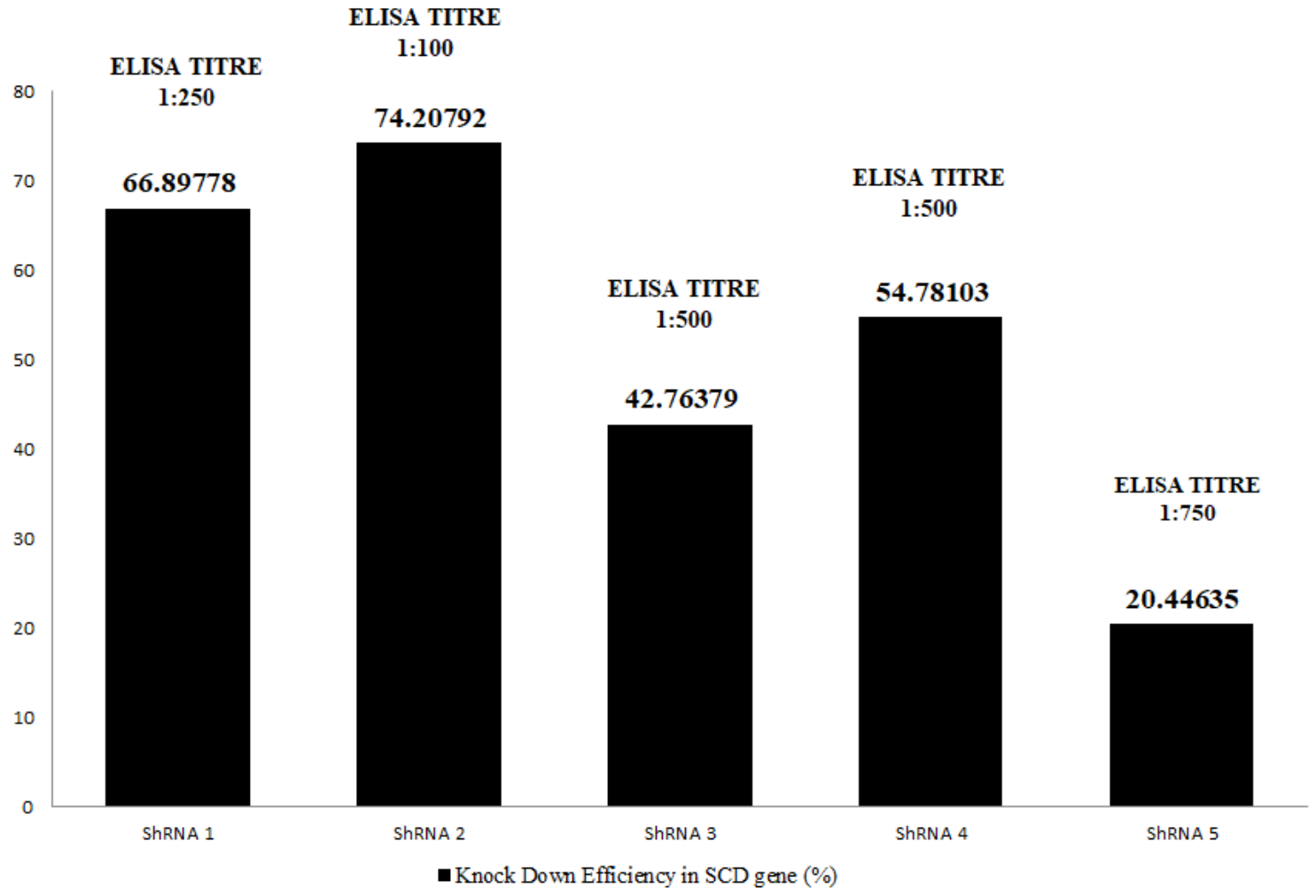

Figure 9

Knock down efficiencies of shRNA molecules of SCD gene and their associated ELISA titres in transfected and control chicken embryo hepatic cells. 


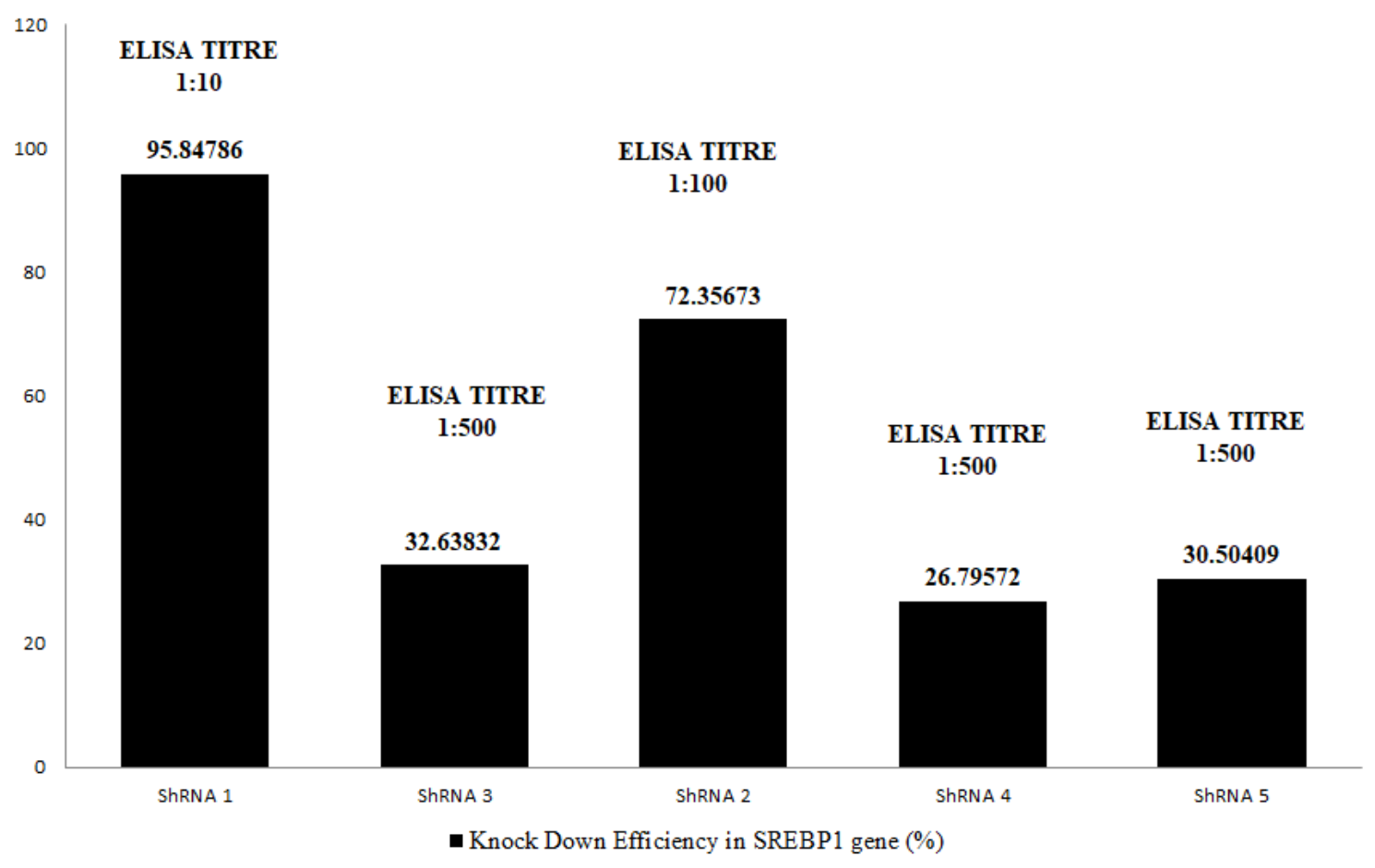

Figure 10

Knock down efficiencies of shRNA molecules of SREBP1 gene and their associated ELISA titres in transfected and control chicken embryo hepatic cells.

\section{Supplementary Files}

This is a list of supplementary files associated with this preprint. Click to download.

- SupplementaryFigures.ppt

- SupplementaryTables.doc

- Supplementarydata1.xls

- Supplementarydata2.xls 